\title{
A IMPRENSA, O INCUNÁBULO E A EMANCIPAÇÃO DO LIVRO IMPRESSO
}

\section{A imprensa como fato histórico.}

A imprensa constitui um dos várics marcos históricos que se situam na fase de transição entre as Idıdes Medieval e Moderna; como um dos prenúncios de nova éra, tem sido freqüentemente adornada com a auréola da miraculosidade, como expoente da engenhosidade humanav

E' indiscutivel que, por suas repercussōes, o aparecimento da imprensa constitui fato histórico de grande importância. No entanto, é necessário que se esclareça que essa nova técnica teria dificilmente deixado de aparecer quando e como o fêz: representa, na réalidade, o resultado de longa evolução material que atingiu no século XV a elaboração final.

A idéia da imprensa é muito anterior ao seu sparecimento como invenção, não sendo mesmo possível assegurar que não tenha atingido a Europa vinda do Extremo-Oriente. Mas, "uma idếia não é uma invenção: Leonardo da Vinci teve a idéia do aeroplano e 1500 anos antes dêle $o$ cientista Hero, de Alexandria, imaginou a máquina a vapor, da qual chegou mesmo a estabelecer os princípios" (1). Paré que uma idéia creadora se transforme em invenção útil, é necessário que haja dois tipos de fatores condicionantes: ambiente favorável à aceitação da invenção e meios materiais sucetíveis de realizar a idéia.

O ambiente social do século XV era tão fívorável à imprensa que é lícito dizer ter havido expectativa em tôrno de seu aparecimento. O humanismo, que surgira na Itália no século anterior, com Bocácio e Petrarca, difunde-se pela Europa no decorrer do século XV; seus seguidores, eruditos entusiastas e imbuidos do princípio $\mathrm{d}=$ liberdade intelectual, relegam várias das crenças $\mathbf{e}$ convenções até então aceitas tàcitamente e passam a estudar não apenas a literatura cristã como também os clássicos latinos e gregos: a reprodução em larga escala de textos antigos passa a ser uma de suas mais caras aspirações. Por outro lado, depois dos Concílios de Constança, Pisa e Basiléia, as ordens religiosas dedicam-se com renovedo vigor à leitura e ac estudo como parte integrante da reimposta disciplina. A intensa atividade intelectual reflete-se no

(1). - Mc Murtrie, The book, p. 123. 
aparecimento de inúmeras universidades e professôres e alunos vão se juntar aos muitos que desejam mais livros e livrcs mais accessíveis. Finalmente, é preciso lembrar ainda a burguesia que, na preocupação da ascenção social, apela intensivamente para o livro como meio de aquisição de cultura e educação.

Pode-se dizer, pois, que o ambiente social estava mais do que preparado para receber a imprensa: estava ancioso por um novo processo que viesse tornar o livro não mais um objeto de luxo, mas um instrumento útil.

Ao lado đa aceitação social tácita, a imprensa conta, na época de seu aparecimento, com boa base técnica pré-existente.

A idéi central do prccesso é em sua essência muito simples, pois reside no conhecimento de que é possivel se obterem reproauções por meio da pressão. De há muito era sabido que qualquer objeto com um desenho em relêvo sôbre uma superfície plana pode ser usado ccmo instrumento de reprodução simplesmente molhando sua superfície ccm tinta ou calcando-o contra material prèviamente amolecido: assim se fizera na utilização dos sinetes, na estamparia de tecidos e na decoração de objetos de cerâmica (2). Infelizmente, não se sabe se e como teria êsse processo sido transferido para a confecção de livros: aqui, como sempre, a história da tecnologia é ainda vasto terreno inexplorado - as evidências são poucas e esparsas e os estưđiosos têm se limitado ao lado estético da questão.

Sabemos no entanto que, quer por adaptação de métodos já conhecidos em outras atividades, quer por redescoberta, houve livros impressos por meio de blocos de madeira gravados para êsse fim. Essa arte foi, como a fabricação do papel, primeiramente conhecida na China; desde o século II (3) ai se teriam impresso livros cujas páginas eram esculpidas na pedre, de modo a deixar em alto relêvo e invertidos, os caracteres e imagens. Mais tarde essas páginas vieram a ser gravadas em madeira; de cada uma dessas tábuas podiam-se tirar um número de provas consideràvelmente grande, bastando para isso passar tinta e comprimir fortemente contra o papel. $O$ impresso xilografado mais antigo que se conhece data de 932 mas sabe-se com segurança que o processo foi utilizado muito antes, pois o Japão, que emprestou da China tôdas as fórmulas técnicas para a execução do livro, já fazia impressão por blocos de madeira no século VIII.

A impressão tabular na Europa é feita de maneira absolutamente aráloga à chinesa, embora seja ainda ponto controvertido - ter havido conexões entre ambas. As primeiras impressões xilográficas européias são feitas em folha única: são figuras de santos, cartas de baralho e calencários, dos quais são conhecidos mais

(2). - Butler, The origin of printing in Europe, p. 30-31.

(3). - Dahl, Histolre du livro ,p. 84. 
de 3000 exemplares, sendo o mais antigo uma imagem da Virgem Santíssima, datada de 1418 . Os primeiros livros xilografados são no entanto contemporânecs da imprensa, pois aparecem em meado do século XV. Sem dúvida alguma, trata-se de umat solução dada ao problema da obtenção de livres mais numerosos e baratos, problema que iria também acarretar a elabor cção da imprensa. Em certo sentido, ao mesmo tempo que precursor do livro impresso uma vez que lhe forneceu a idéia básica - o livro xilografado é também seu compstidor. A rivalidade no entanto nuncal chegou a ser séria, pois que o livro xilcgrafado, devido à própria técnica, dá maior ênfase às ilustraçōes, restringindo o texto ao máximo, especializando-se em assuntos eminentemente populares, como livros religiosos ("Biblia. Pauperum", "Speculum Humanae Salvationis" e "Ars Morriendi", entre cs mais comuns) calenđários e gramáticas latinas (como a de Donatus).

Além de ser conhecida a técnica da reprodução por compressão, parece terem sido utilizados, antes do aparecimento da impren$s \equiv$, os caracteres móveis. No que se refere ao uso dêstes na China, não é possível haver dúvidas, havendo documentos que se referem ao emprêgo de "caracteres móveis de argila cozida, mais tarde de cobre e chumbo" (4) no século XI. No entanto; foram posteriormente abandonados, provàvelmente devido às dificuldades nascides do enorme número de símbolos da escrita chinesa, voltando-se ao processo dás placas de madeira, usadas até hoje. Mais uma vez, não se sabe se houve difusão do Oriente para o Ocidente ou se houve redescoberta; o fato é que Gutemberg já encontrou caracteres móveis. Com o pequeno número de letras do alfabeto. ocidental, o sucesso foi fácil e também aqui encontramos uma iciśia que, de tão óbvia, deve ter ocorrido a muitos; há quem considere como o inventor dos caracteres móveis o holandês Lcurenço Costet (Laurens Janszoon Coster), donde ter disputado, no julgamento da posteridade, a glória de ter sido o "pai da imprensa".

Com a expectativa reinante e a base técnica existente, é lícito dizer que, em meado do século XV, a imprensa "estava no ar". Parece mesmo que várias pessoas teriam tr:balhado simultaneamente na idéia, haja visto as trevas que envolvem a história de seu aparecimento $e$ as reivindicaçōes feitas em tôrno dos nomes de vários inventores presumiveis.

Difìcilmente se pcde falar, adeqü:damente, em "invenção" da imprensa; o que foi feito, segundo a cpinião agora generalizada entre os historiadores, foi obra de Gutenberg (1400-1468), consistindo apenas na solução dos problemas ainda existentes e que impediam o funcion $=$ mento da imprensa.

Os problemas resolvidos por Gutenberg (provàvelmente em 1440) foram: dimensão dos caracteres móveis, metal adeqüado ao

(4). - Dahl, op. cit. p. 86 . 
trabalho tipográfico, tinta adaptada às superfícies metálicas e prensa especial para a produção de livros. O problema dimensional dos caracteres móveis levou-o a desenhar, gravar e fundir os primeiros tipos de propcrçóes acuradas, de modo a produzirem 1inhas horizontais, espaços iguais, margens direitas retas e impressão homogênea: são os "tipos Gutenberg", com os quais imprimiu a "Bíblia de 42 linhas" (5). Qu:nto ao metal, era preciso que se encontrasse um de resistência suficientemente grande para resistir à lixívia e ao desgaste e não tão grande que fôsse difícil de fundir ou rasgasse o papel; depois de inúmeras tentativas, Gutenberg chegou à liga de entimônio e chumbo, preenchendo de tal modo os requisitos necessários que é até hoje empregada. Abandonando-se a madeira e adotando-se 0 metal, tcrnou-se necessária nova tinta tipográfica, mais grossa, o que Gutenberg solucionou com a edoção da tinta à base de óleo de linhaça. Restava, finalmente, a prensa que simboliza todo o processo: a sua utilização se impunha porque a tinta oleosa e o papel europeu, menos flexível que o oriental, exigiam pressōes fortes. A prensa já existia, sendo utilizada no esmagamento de uvas para a fabricação de vinho e na confecção do papel - para retirar o excesso de humidad'; Gut=nbsrg Edaptou - aparelho já conhecido às necessidades tipcgráficas, colocando-o à altura de uma mesa e acrescentando-lhe uma moldura para fixar o papel.

Gutenbsrg, pois, não "inventcu", pròpriamente, a imprensa: chegou apenas à sua elaboração finel; que nada tem de "miraculoso" ou "genial", sendo, quando muito, inteligente.

\section{Os primeiros hivros impressos.}

Resultado final de longa evolução técnica, a imprensa não tem, ao aparecer, caráter revolucionário: sua finalidede era apenas executar o trabalho do copista de maneira mais rápida e econômica. Os primeiros livros impressos - "incunábulos" - (6) procuram não quebrar trađições, ad:ptando as convençōes existentes à nova técnica: são, por assim dizer, "manuscritos impressos".

Os característicos principais do manuscrito passam para $O$ incunábulo. O formato é grande, mais freqüentemente in-4; os caracteres tipográficos são góticos, com exceção da Itália, onde os tipos romanos têm aceitação precoce; a composição divide o texto nas clássicas duas colunas, deixando margens enormes para recebe-

(5). - Assim chamada porque cada coluna do texto contém 42 linhas. f também conhecida como "Biblia Mazarina", derido zo fato do primeiro exemplar estudado ter pertencido à. biblioteca de' Mazarino.

(6). - Do latim "cunabulum" - berço. O têrno foi inicialmente empreEado para designar os primeiros livros impressos calcados sobre o manuscrito; seriam. aproximadamente, os liuros impressos na Europa ocidental ate 1500 e na Europa setentrionil até 1550 . Posteriormente o tijmo tomou sentido mais generico, passando a designar os primeiros livros inpressos de um pais, independentemente de seus caracteristicos ou de data. 


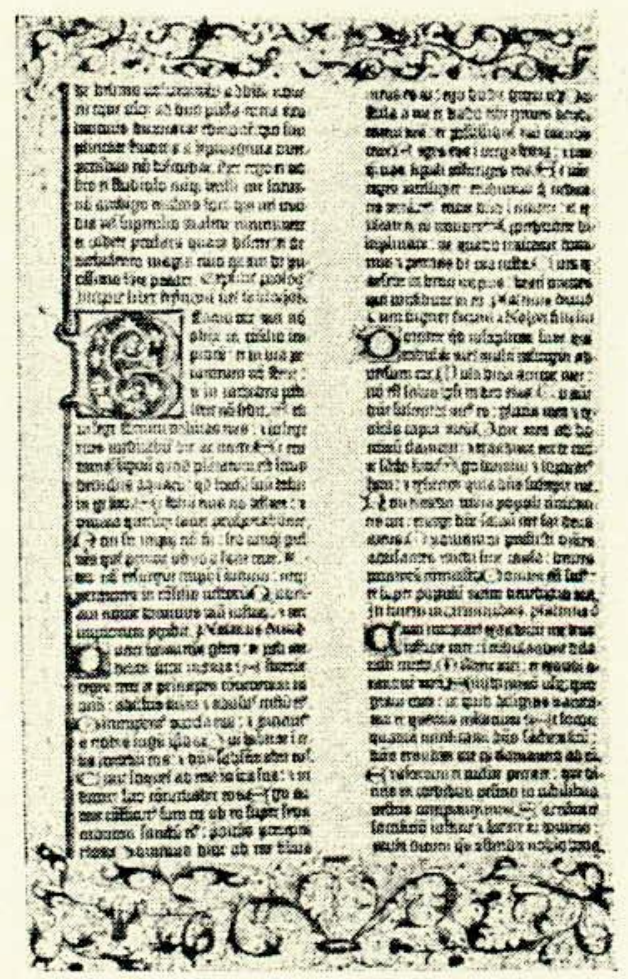

Fig. 1. - Página da "Bíblia de 42 linhas", impressa por Gutenberg em 1456. Apud Dahl, p. 92. 


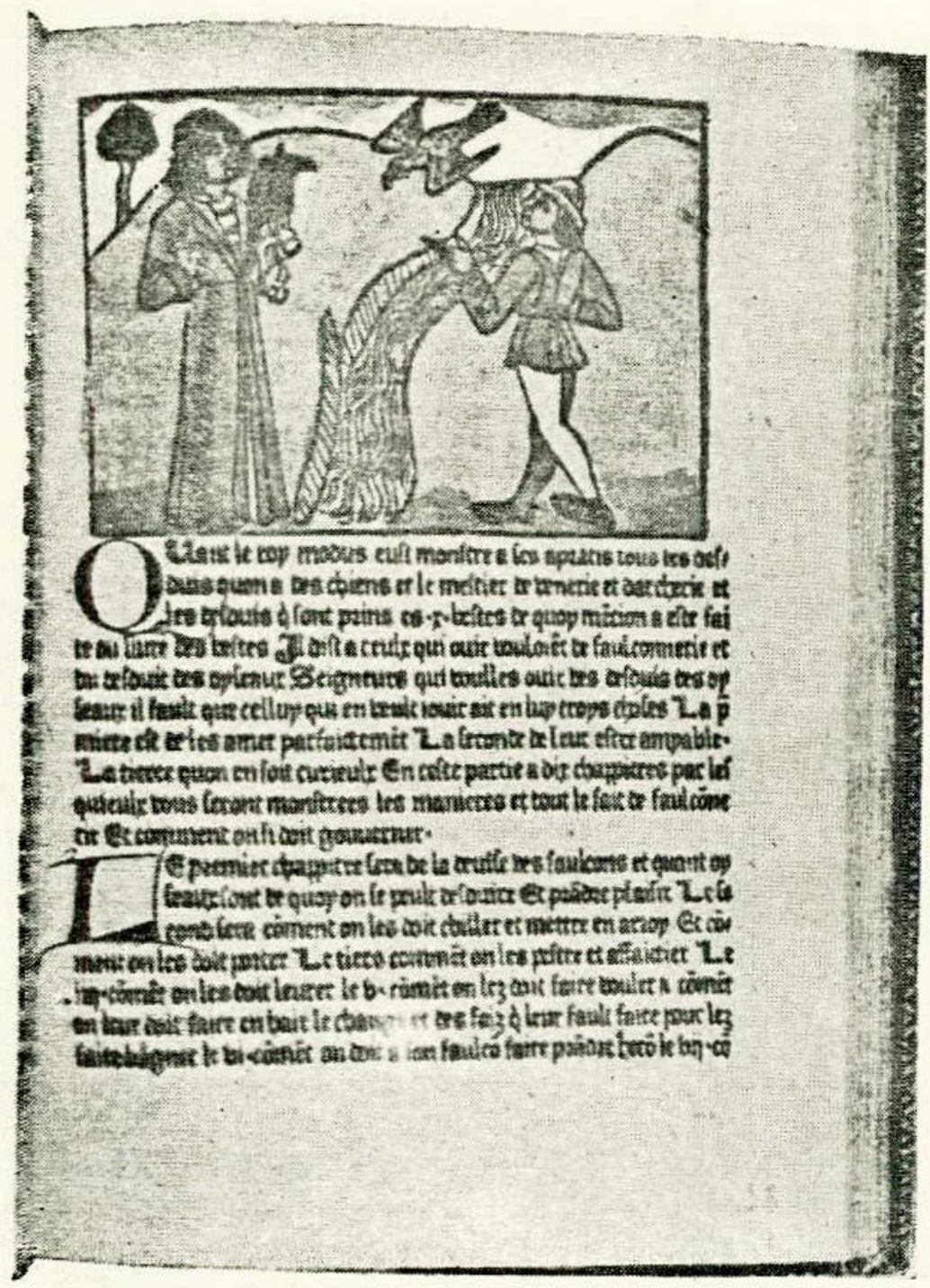

Fig. 2 - Pagina de "Le livre du roy Modus", impresso por Antoine Neyret em 1486. Apud Lejard, p. 51. 
tem decoração acrescentada à mão e espaços em branco para as letras iniciais e capitais, também colocadas manualmente. Para maior semelhança, a página de rosto continua inexistente no incunábulo; êste contava, quando muitc, como o "incipit" ou "hic incipit”, palavras de introdução que vinham como cabeçalho ao texto; a impresa aparecia no fim do livro, em forma de longa frase explicativa - o colofão.

Exemplos de incunábulcs típicos encontramos entre a própria produção de Gutenbsrg, principalmente na sua Bíblia de 42 linhas (7) (vide gravura 1), e na de Füst e Schöffer, que durante algum tempo foram sócios do primeiro e que depois, trabalhando sòzinhos, chegaram a equiparar cu mesmo sobrepujar a técnica e gôsto artístico do mestre. De Füst e Schöffer temos um trabalho, o "Psaltéric de Mogúnci $\varepsilon$ ", considerado como uma das obras primas entre os incunábulos: coleção de cânticos para a utilização em côros religiosos, a música aparece acrescentada à mão em espaços prèviamente reservados para ésse fim; o texto foi impresso em preto, com iniciais alternadamente em vermelho e azul e capitais combinando as duas côres. Este livro tem, além de sua grande beleza, o interêsse de ter sido o primsiro a indicar claramente ter sido impresso, como se pode verificar pelo seu colofão: "Esste volume de Psalmos, adornado $\mathrm{ccm}$ a magnificênci : de letras capitais e claramente dividido por rubrices, foi obtido por meio de processo mecânico de impressão e produção de caracteres, sem auxílio da pena, e foi laboriosamente completado, para a Glória de Deus, por Johann Füst, cidedão de Mogúncia e Peter Schöffer, de Gernsheim, na véspera da. Assunção, no ano do Senhor de 1457" (8).

Vergados ao pêso das heranças do manuscrito, os primeiros livros impressos podem ser acusados de falta de originalidade. São no entanto, de grande beleze, assombrando pela perfeição da técnica. Enriquecidos pela decoração, pelas encadernações luxuosas, acabam vencendo até mesmo os escrúpulos dos cclecionadores, saíndo vitoriosos na luta como suceđâneos, ou substitutos, do livro manuscrito. Mas felthavam num ponto: eram ainda demasiadamente dispendiosos à aquisição popular, devido à boa proporção de trabalho manual que exigiam.

Visando o barateamento do livro, os primeiros tipógrafos logo se afastam de seus modelos manuscritos em relação à ilustração e decoração: adotam a gravura sôbre madeira - xilogravura, cujo bloco era imbutido na composição e impresso ao mesmo tempo que o texto.

No início, a xilogravuraı só fornece o esbôço das imagens, posteriormente coloridas a mão; são gravuras primitivas e simples, freqüentemente repetidas em diversos livros para ilustrar assuntos 
completamente diferentes (vide gravura 2). Acs poucos, taivez pelo grande aumento da producão, talvez vizando sempre o baratexamento, abandone-se o colcrico $a$ adotem-se as gravuras em bratco e preto: ao nesmo tempo, estabeleccm-se as "ilustraç̃es de ediçäo": err gue as gravurés, se?uindo de perto o texto, póem èn. fase no assunto, interpretando- com auniratel propriedade. São ainda figuras primitivas. com linhas simplificadas, com fatua de perspectiva. mas que combinam bern com os caracteres cheios e pesados. dos quais se destacam mesmo quando há ausencia de moldusa (vide gravura 3) (9). Finalmente, afim de vencer a decorecäo a mão, a xilografia vai acusando aperfeicoamentos cada vez maiores; contra ela, contava com a ausência de cố e para compensá-la a xilogravura recebe requintes de cuidados rninuciosos; chegando a atingir alto nível artísticc, assinadas por grandes nomes do período (vide gravura 4). Neste periodo, pelo menos quanto à técnica, a ilustraça de livros já está muito distante dos manuscritos; faltava apenas uma renovação nas concepcões artísticas para que se completasse a emancipação do invo impresso.

\section{A enancipacâo tic lwro tmprese}

A tencvacăo das concepçöes artísticas em relaçäo ao livro vem por influéncia da Renascença. O ideal clássico, saíndo do dominio da arte pura para entrar no da cute aplicada, irá substituir os caracteres góticos por romanos ou latinos, abandonar na decoração e ilustração os motivos e estilo medievais para adotar personagens, enquacoramentos e capitais de inspiração nitidamente greco-romana.

E' natural que näo se possam fixar limites cronológicos rígidos para os diferentes períodos artísticos da história do livro: enquanto que, no comêço do século XVI, a França ainda apresenta um Vérard que, com seus "livres de horas", continua a "imprimir manuscritos", a Itália já tinha no século XV seus representantes da Renascença, como Ratold. Êste pod E ser considerado como - verdadeiro pioneiro da renovação artística do livro: seus tipos romanos, inspiratos na caligrafia cerolíngie, suas capitais e enquadramenios com motivos de flora estilizacios em contrastes vioientos de branco e preto, dão às suas obras um sabor definitivamente cíássico (vide gravura 5 ).

No emtanto, o grande nome dE renascença tipográfica, é o de. Aldus Manutius (10). Discípulo de Pico de Mirandola, sábio e humanista de grande valor, Aldus não se tornou impresscr por inurêsse direto na tipegrafia, mas porque esta era o meio para atin-

(4). - Alecmas san täo arcaicas em estilo que somos levedos a pensar que

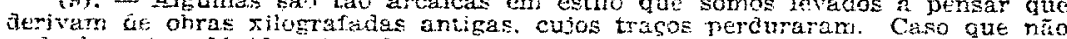

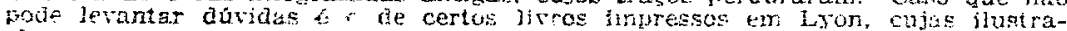

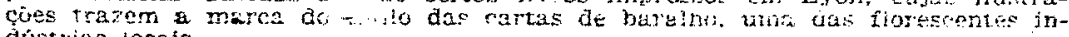
fusirias tocais.

[10). - Ado Manzzzio, no originas. 


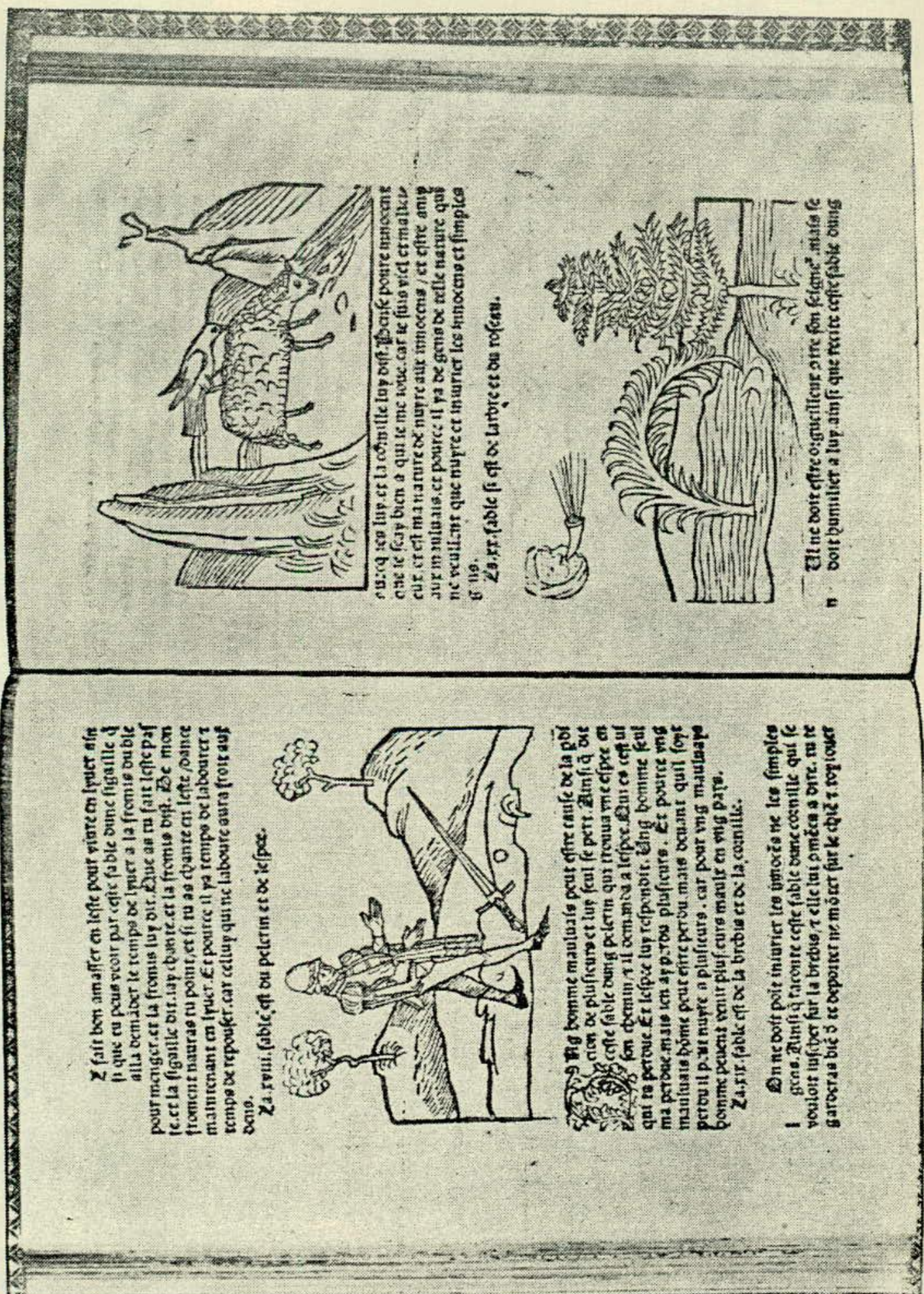

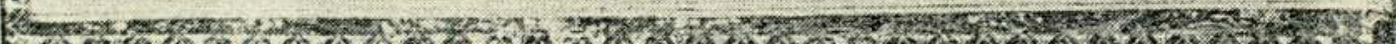

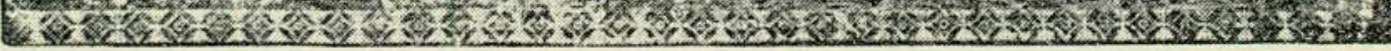

Fig. 3. - "Fábulas de Esopo", impresso em Lyon, em 1484. Xilogravura em branco e preto. Apud Lejara, p. 49. 


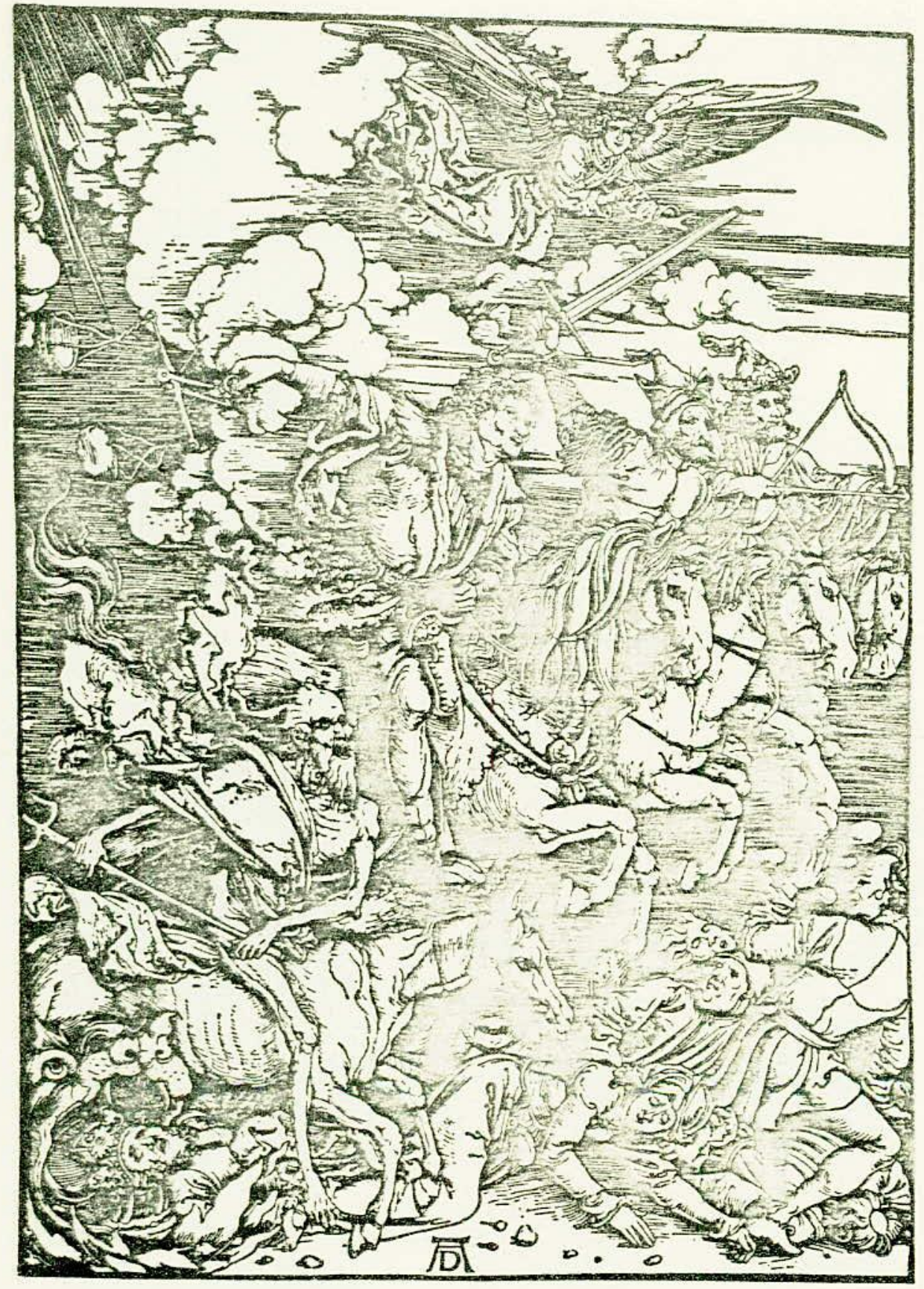

Fig. 4. - Os "Quatro cavalheiros do Apocalipse". desenho de Alhrecht Dürer, impresso em Nurenberg, em 1498. Apud Mic Murtrie, p. 247. 


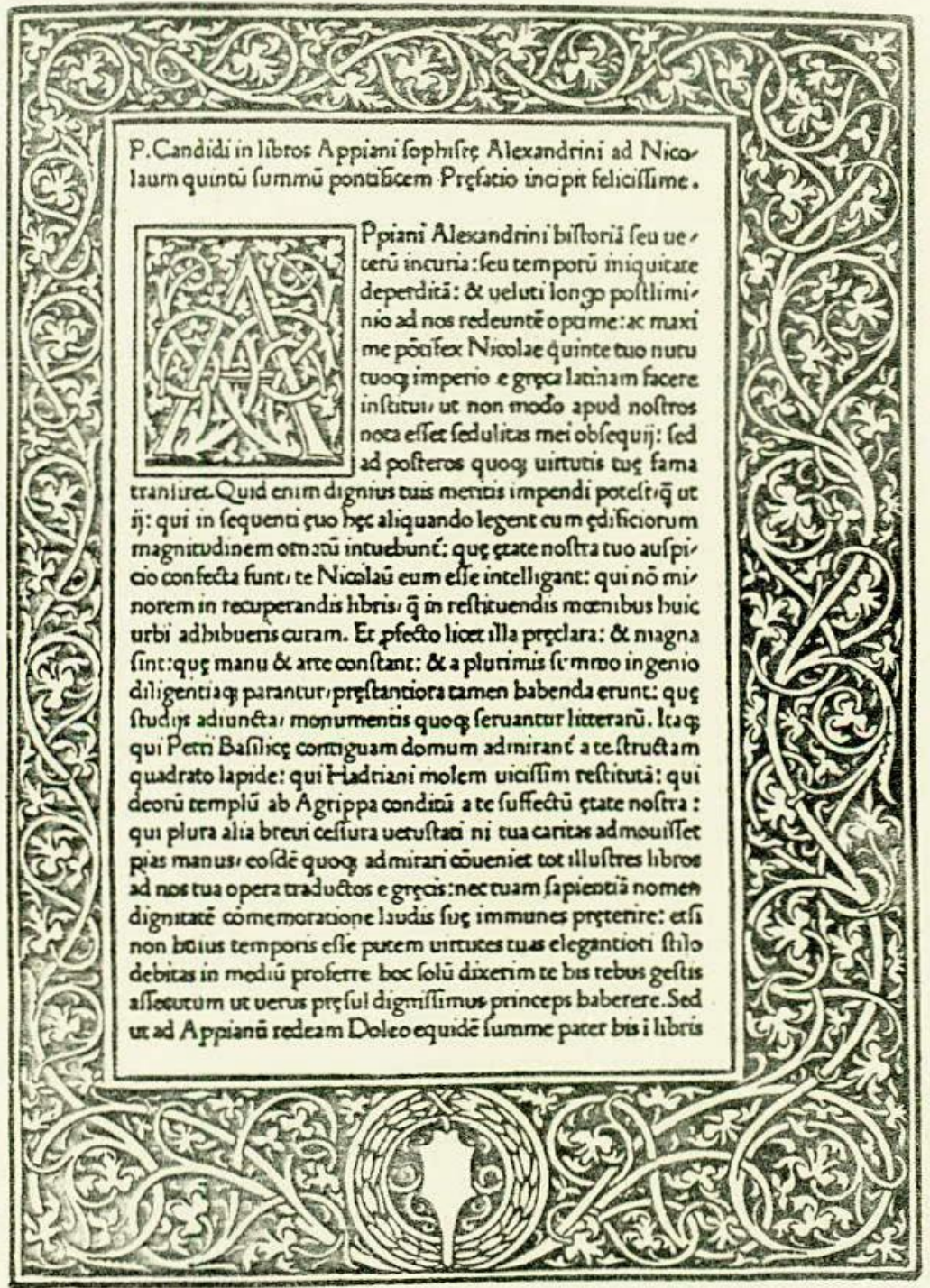

Fig. 5. - Página do "De Bellis Civilibus". de Apiano. Impresso por Ratoldt, Veneza, em 147\%. Apud Mc Murtrie, p. 270. 


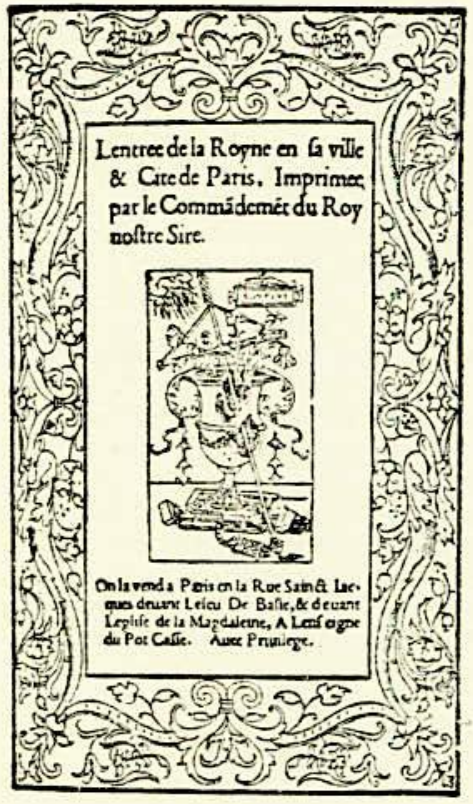

Fig. 6. - lúgina de rosto de "L entrée de la Keine à Paris". impresso por Tory. Apud Dahl. p. 151. 
gir o fim que procurava! a produção de edições criticas e corretas dos escritores clássicos. Para isso cerca-se de eruditos; formando a "Academia Aldina", centro de estudo e discussão dos textos antigcs que deveriam ser editadcs. Dotado de espirito prático e artístico, sua produção tipográfica ficou, no entanto, marczdà por sua personalidade. Pera tornar o livro mais cômodo, introduz a capa cartonada (11) e o formato in-8: aparecia assim o primeiro "1ivro de bolso", pequeno, leve e de fácil manuseio. No que se refere à decoração, Aldus vai adotar os mesmos enquadramentos e frisos de Ratoldt, mas em estilo mais leve, com deseni.ss a traço sôbre fundo branco livre de qualquer sobrecerga. A alta significaŁ̧ão do trabalho dêste grande impressor italiano é freqüentemiente esquecida atualmente, embcra seu nome, ligado ao tipo "itálico", đe sua invenção, faça parte do vacabulário técnico corrente do tipógrafo. Da mesma forma, sua marca de editor - o delfim enrolado à âncora - aparece ainda como motivo decorativo e como o próprio símbcle da imprensa: atividade e velocidade aliadas à segurança estabilidede.

A renascença faz sua aparição na Fratça com Geoffroy Tory: conhexendo os trabalhos de Aldus por ocasião de duas viagens à Itália, passé a introduzir no livro francês suntuosos encquadramentcs a traço ou em contraste de branco e preto maciços, mostrando claramente a influência italiana. (12)

Outto grande representante da renascença tipográfica é Cristovão Plantino, de Antuérpia, que, embora menos inovador que Tory e de menos valor que Aldus, contribuiu muito para a difusão das novas concepcōes, por ser proprietáric de grande casa editora com sucursais por tôdà a Europa.

Aos poucos, com o impulso dado por um pequeno punhado de tipógrafos avançadcs, o livro impresso vai tomando aspecto completamente diferente do manuserito, impindo-se por si mesmo e năo mais como sucedâneo.

O único pais em que a renascença pouco vai influir na renoveção do livro-é a Alemañha, code, no entanto, nascera a imprensa. O nivel tipográfico da Alemanha, no decorrer do século XVI, é sensivelmente inferior ao de seus vizinhos; fora alguns trabalhos de ilustraçäo de grande valor, como ò de Hans Holbein e Dürer, - livro alemão mantém os tipos góticos, é antiquado e feio quando em comparação com o italiano ou francês. A pequena influência da renascença na tipografia alemã só pode ser explicada pelo fato de ter sido neutralizada, até certo ponto, pela eclosão de outra corrente de idéias - a Reformá Protestante.

(11). - Em lupar das de madeira. usadas ate então.

(12). - Na travura 6 pode-se ver um bom exenmio de seus trabalhos, especialmente interessante por incluir kua marca de editor. Ieitu for ocksiä da morte de sua filha: o pote quebrado por seta vinda do céu com a legenda, "Non plus". 
A luta empreendida por Lutero contra a Igreja Romana foi o sinal de grandes modificaçôes, que não deixa de influir na história do livro. Nos anos que se seguiram à introdução da Reforma, torrentes de panfletos inv ¿diram a Alemanha; é evidente que essas pequenas publicaçooses, de titulos frecüuntemente provocantes, só podiam levar em consideráacão os crnamentos mais indispensáveis. Trata-se de literaturé de circunstancia, que só podia ser rendid.a a baixo preço efim de cumprir com sua missão agitadora.

A modernização do livro alemão vai ser por êsse motivo tardia, prejudicada nasis uma vez, no séculc XVII, pelas conseqüências desastrosas da Guerra de 30 anos; só no século XVIII a Alemanha consegue alcançar o nivel de produção da França e da Itália, quanco, já em pleno classicismo, ensaia a introdução de caracteres góticos fortemente influenciados pelo tipo romano do tipó grafo francès Didot.

Mas, apesar de discrepáncia do livro alemão, pode-se dizer que o século XVI é, verdzdeiramente, a "éra de ouro" do livro impresso, pois marcai sua emencipaçãa. Os impressores desse periodo não copiaram estilos anteriores, mas abriram terreno para o estabelecimento $a_{i}$ novas concepçós, cuja beleza e harmonia têm servido de inspirceão para os melhores tipógrafos dos últimos trezentos e cinccent anos.

\section{NICE LECOCQ-MÚLLER}

Frofessora da Cadeina de Histonia do Huro da Escola de Eibioteconomia anexa de Escola de sociolosia e Politica de Säo pauio.

\section{BIBLIOGKAEIA}

1. Audiz, Marius - Le Iivre. Paris, Auguste Aubry, s.d.

2. Butler, Pierce - The origin of printing in Europe. Chicago, University Press, 1940.

3. Dahy, Svend - Histoire du livre: de lantiquité à nos jours. Paris. Jules Lamarre; 1933.

4. Dupont. Faul François - Histoire de l'imprimerie. Paris, Paul Dupont. 1854.

5. Egger, Emile - Mistoire du livre depuis ses origines jusqu'a nos jours. Paris. Bibliothèque déducation et de récreation. s.d.

6. Fumagall. G. - Bibliografia. Milane. Hoepli 1935.

7. Lejarc. André - The art of the french book. London. Paul Elek, s.d.

8. Louisy, M. P. - Le live et les arts qui s'y rattachent, depuis les origines jusqua la tin du XVUleme. siecle. Paris, Firmin-Didot, 1887.

9. Mc Murtrie. Douglas - The book - the story of printing and bookmithing illustrated. Londan. Oxford University Press. 1948.

10. Moravit. Gustave - Le livre. Paris, Auguste Aubry, s.d.

31. Mortet, Charles - Les origines et les dẻbuts de l'imprimérie. Paris, Societe française de bibliographie, 1922.

12. Wroth, Lawrence C. - A bistory of printed book. New York, 1938. 